\title{
ORIGINAL
}

\section{Effects of gender and body weight on fibroblast growth factor 23 responsiveness to estimated dietary phosphorus}

\author{
Hiroyuki Ohta', Masae Sakuma1, Akitsu Suzuki', Yuuka Morimoto¹, Makoto Ishikawa², Minako Umeda², \\ and Hidekazu Arai ${ }^{1}$ \\ ${ }^{1}$ Laboratory of Clinical Nutrition and Management, Graduate School of Nutritional and Environmental Sciences, The University of Shizuoka, \\ Shizuoka, Japan, ${ }^{2}$ School of Nursing Sciences, The University of Shizuoka, Shizuoka, Japan
}

\begin{abstract}
Fibroblast growth factor 23 (FGF23) is a molecule involved in regulating phosphorus homeostasis. Although some studies indicated an association between serum FGF23 levels and sex, the association has not been fully investigated. The purpose of this study was to evaluate whether sex could influence FGF23 responsiveness to dietary phosphorus intake in healthy individuals. Thirty two healthy subjects between 21 and 28 years were recruited for this study. Subjects performed 24 -hour urine collection and blood samples were collected. We estimated phosphorus intake (UC-P) from the urine collection (UC), and evaluated any association between UC-P and serum FGF23 levels. Subsequently, we compared serum FGF23 levels between males and females. Positive correlation was observed between UC-P and serum FGF23 levels. Serum FGF23 levels were significantly higher in males than in females. Serum FGF23 levels/UC-P was significantly higher in females than in males. There was no significant difference in serum FGF23 levels/UC-P/BW between the male and female groups. Our results indicate that there was no gender difference between FGF23 responsiveness to phosphorus intake per body weight. J. Med. Invest. 63 : 58-62, February, 2016
\end{abstract}

Keywords : dietary phosphorus intake, serum FGF23 levels, sex, body weight, 24-hour urine collection

\section{INTRODUCTION}

Phosphorus is an important constituent of nucleotides and is essential for bone mineralization, muscle function, cellular signal transduction, and energy storage (1). Serum phosphorus levels are usually maintained in the normal range of $2.5 \mathrm{mg} / \mathrm{dl}$ to 4.5 $\mathrm{mg} / \mathrm{dl}$, however, disorders of the kidney decreases phosphorus excretion in the urine and increases serum phosphorus levels.

It has been reported that an increase in serum phosphorus levels induces vascular calcification, arterial sclerosis, cardiovascular disease and mortality among renal patients (2-4). It was recently reported that a high phosphorus intake increases serum phosphorus levels and impairs endothelial function, even in healthy individuals (5). Therefore, it is advisable that both kidney failure patients and healthy individuals should avoid having too much phosphorus. In healthy individuals with normal renal function, phosphorus homeostasis is tightly controlled by several factors, such as parathyroid hormone (PTH), fibroblast growth factor 23 (FGF23) and 1,25-dihydroxyvitamin D $\left(1,25(\mathrm{OH})_{2} \mathrm{D}\right)(6-10)$. These factors maintain serum phosphorus levels through the control of renal phosphorus excretion and intestinal phosphorus absorption.

FGF23 is a recently identified molecule, involved in regulating phosphorus homeostasis (11-13). Secretion of FGF23 is stimulated by an increase in serum phosphorus levels, and principally acts in the kidney to regulate phosphorus metabolism. FGF23 reduces serum phosphorus levels by at least two mechanisms : 1 ) it decreases renal phosphorus reabsorption by lowering renal sodium-phosphorus transporter $(\mathrm{NaPi}) 2 \mathrm{a}$ and $\mathrm{NaPi} 2 \mathrm{c}$ expression and 2) it decreases intestinal phosphorus absorption by

Received for publication July 9, 2015 ; accepted October 13, 2015.

Address correspondence and reprint requests to Masae Sakuma, Ph.D, Laboratory of Clinical Nutrition and Management, Graduate School of Nutritional and Environmental Sciences, The University of Shizuoka, 52-1 Yada, Suruga-ku, Shizuoka 422-8526, Japan and Fax : +81-54-2645511. diminishing plasma $1,25(\mathrm{OH})_{2} \mathrm{D}$ levels which inhibiting $1 \alpha$-hydroxylase and stimulating 24-25hydroxylase activities. It has been reported that high phosphorus loading increases serum FGF23 levels (6-8). FGF23 is synthesized in osteocytes, and it has been reported that various factors involved in bone metabolism, such as phosphate regulating genes with homologies to endopeptidases on the $\mathrm{X}$ chromosome (PHEX), dentin matrix protein 1 (DMP1), and estrogen, influence its synthesis (14).

Estrogen is one of the factors affecting bone metabolism and recent studies found that administration of estrogen increased serum FGF23 levels in ovariectomized rats (15). In the Heart and Soul Study, serum FGF23 levels were significantly higher in postmenopausal females compared with males, and were decreased by estrogen therapy (16). Although some studies have indicated at an association between serum FGF23 levels and sex, the association has not been fully investigated. It remains unclear whether secretion of FGF23 in response to dietary phosphorus intake is affected by sex. The purpose of this study was to evaluate whether sex influences FGF23 responsiveness to dietary phosphorus intake in healthy individuals.

\section{MATERIALS AND METHODS}

\section{Subjects}

Thirty two healthy subjects (14 males and 18 females) between 21 and 28 years were recruited for this study. We performed anthropometric measurements and biochemical examinations of blood to show that subjects had no health problems. The clinical and biological characteristics of the subjects are shown in Table 1. All subjects gave written informed consent and the ethical committee of the University of Shizuoka approved this study. The protocol conformed to the Helsinki Declaration. 
Table 1. Characteristics of the subjects and sex comparison.

\begin{tabular}{|c|c|c|c|c|c|c|c|c|c|c|c|}
\hline \multirow[b]{2}{*}{ Age } & \multirow[b]{2}{*}{ (year) } & \multicolumn{3}{|c|}{$\begin{array}{c}\text { Total } \\
(\mathrm{n}=32)\end{array}$} & \multicolumn{3}{|c|}{$\begin{array}{c}\text { Male } \\
(\mathrm{n}=14)\end{array}$} & \multicolumn{3}{|c|}{$\begin{array}{c}\text { Female } \\
(\mathrm{n}=18)\end{array}$} & \multirow[t]{2}{*}{ P value } \\
\hline & & 22.8 & \pm & 2.0 & 22.8 & \pm & 2.0 & 21.5 & \pm & 0.7 & \\
\hline HT & $(\mathrm{cm})$ & 164.4 & \pm & 9.6 & 172.5 & \pm & 6.7 & 158.1 & \pm & 6.0 & $<0.01$ \\
\hline BW & $(\mathrm{kg})$ & 57.3 & \pm & 10.8 & 65.7 & \pm & 10.8 & 50.8 & \pm & 4.7 & $<0.01$ \\
\hline BFP & (\%) & 21.4 & \pm & 5.8 & 18.6 & \pm & 4.9 & 24.3 & \pm & 4.7 & $<0.01$ \\
\hline LBM & (kg) & 44.5 & \pm & 9.2 & 53.1 & \pm & 6.7 & 37.7 & \pm & 3.6 & $<0.01$ \\
\hline BMI & $\left(\mathrm{kg} / \mathrm{m}^{2}\right)$ & 21.1 & \pm & 2.7 & 22.0 & \pm & 2.7 & 20.4 & \pm & 2.5 & 0.11 \\
\hline TG & $(\mathrm{mg} / \mathrm{dL})$ & 62.3 & \pm & 29.7 & 72.4 & \pm & 35.4 & 54.5 & \pm & 22.4 & 0.16 \\
\hline LDL-c & $(\mathrm{mg} / \mathrm{dL})$ & 93.3 & \pm & 24.2 & 87.0 & \pm & 26.4 & 98.2 & \pm & 21.8 & 0.20 \\
\hline HDL-c & $(\mathrm{mg} / \mathrm{dL})$ & 63.4 & \pm & 12.4 & 58.3 & \pm & 8.2 & 63.4 & \pm & 12.4 & $<0.05$ \\
\hline $\mathrm{HbA1c}$ & (\%) & 4.9 & \pm & 0.2 & 4.9 & \pm & 0.2 & 5.0 & \pm & 0.2 & 0.38 \\
\hline $\mathrm{TP}$ & $(\mathrm{g} / \mathrm{dL})$ & 7.4 & \pm & 0.4 & 7.4 & \pm & 0.5 & 7.5 & \pm & 0.4 & 0.52 \\
\hline Alb & $(\mathrm{g} / \mathrm{dL})$ & 4.8 & \pm & 0.3 & 4.8 & \pm & 0.3 & 4.7 & \pm & 0.3 & 0.70 \\
\hline UN & $(\mathrm{mg} / \mathrm{dL})$ & 12.8 & \pm & 2.8 & 13.3 & \pm & 3.2 & 12.4 & \pm & 2.5 & 0.34 \\
\hline Cre & $(\mathrm{mg} / \mathrm{dL})$ & 0.73 & \pm & 0.14 & 0.86 & \pm & 0.09 & 0.63 & \pm & 0.06 & $<0.01$ \\
\hline $\mathrm{Na}$ & $(\mathrm{mEq} / \mathrm{L})$ & 140.7 & \pm & 1.4 & 140.9 & \pm & 1.4 & 140.5 & \pm & 1.3 & 0.28 \\
\hline $\mathrm{K}$ & $(\mathrm{mEq} / \mathrm{L})$ & 4.2 & \pm & 0.3 & 4.1 & \pm & 0.3 & 4.2 & \pm & 0.3 & 0.46 \\
\hline $\mathrm{Cl}$ & $(\mathrm{mEq} / \mathrm{L})$ & 104.4 & \pm & 1.5 & 104 & \pm & 1.4 & 104.7 & \pm & 1.4 & 0.17 \\
\hline $\mathrm{Ca}$ & $(\mathrm{mg} / \mathrm{dL})$ & 9.5 & \pm & 0.3 & 9.6 & \pm & 0.3 & 9.5 & \pm & 0.2 & 0.20 \\
\hline $\mathrm{Pi}$ & $(\mathrm{mg} / \mathrm{dL})$ & 4.0 & \pm & 0.4 & 3.7 & \pm & 0.5 & 4.2 & \pm & 0.3 & $<0.01$ \\
\hline PTH & $(\mathrm{pg} / \mathrm{mL})$ & 42.8 & \pm & 12.4 & 44.9 & \pm & 14.1 & 41.2 & \pm & 2.6 & 0.41 \\
\hline
\end{tabular}

Data are means \pm SD.

HT, height ; BW, body weight ; BFP, body fat percentage ; LBM, lean body mass ; BMI, body mass index ; TG, triglyceride ; LDL-c, low density lipoprotein-cholesterol ; HDL-c, high density lipoprotein-cholesterol ; HbA1c, hemoglobinA1c ; TP, total protein ; Alb, albumin ; UN, urea nitrogen ; Cre, creatinine ; Na, sodium ; K, potassium ; $\mathrm{Cl}$, chlorine ; Ca, calcium ; Pi, phosphorus ; $\mathrm{PTH}$, intact parathyroid hormone.

Two sample t-test or Mann-Whitney test was used for compare male and female.

\section{Protocol}

This study was implemented according to a previously published method (17). Subjects performed 24-hour urine collection and weighed dietary records. Subjects were asked to avoid participation in heavy exercise during the study. Subjects weren't limited in any other activities or dietary intake and were prescribed to spend a day as normal. On the following morning, dietary records, pictures of foods consumed and 24-hour urine samples were collected, in addition, blood was taken after sufficient rest. Subjects participated three times in these exams with at least one day intervals.

\section{4-hour urine collection method}

Subjects performed the 24-hour urine collection method using URIN-MATEP (Sumitomo Chemical Co. Ltd., Tokyo, Japan), which could accumulate $1 / 50^{\text {th }}$ of whole urine, over a 24 -hour monitoring period. Subjects were instructed to discard the first morning void and to collect all urine over the following 24 -hours, including the first void on the next morning. After weighing the total volume of urine from each individual, samples were dispensed them into vessels for storage at $4^{\circ} \mathrm{C}$ or $-30^{\circ} \mathrm{C}$ until use. The analysis company, SRL Inc, (Tokyo, Japan) measured urine nitrogen levels, creatinine levels and inorganic phosphorus levels. Weighed dietary records often over- or underestimate phosphorus intake because it does not add phosphorus derived from food additive, fluctuations in phosphorus content due to cooking loss and production region and picking seasons are not considered. We reported that the 24hour urine collection method can estimate the amount of dietary phosphorus intake, and were superior to estimation by weighed dietary record (17). So, we calculated the daily dietary intake, estimated from the urine collection (UC), of phosphorus (UC-P).
We calculated UC-P based on a report that phosphorus absorption was about $65 \%$ (17).

UC-P (mg/day) = urine phosphorus excretion $(\mathrm{mg} /$ day $) / 0.65-$ (1)

\section{Anthropometric and biochemical examinations of blood}

Height, body weight, body fat percentage and lean body mass were calculated using a bioelectrical impedance analysis method (TANITA TBF-215 ; TANITA Corporation, Tokyo, Japan). Body Mass Index (BMI) was calculated using the following formula :

$\mathrm{BMI}=$ body weight $(\mathrm{kg}) /$ body height $(\mathrm{m})^{2}$ - (2)

Blood samples were dispensed into vacuum blood collection tubes and centrifuged ( $\left.4^{\circ} \mathrm{C}, 3000 \mathrm{rpm}, 10 \mathrm{~min}\right)$ immediately. Serum and plasma samples were separated and stored at $-30^{\circ} \mathrm{C}$ until use.

Triglyceride (TG), low-density lipoprotein cholesterol (LDLCho), high-density lipoprotein cholesterol (HDL-Cho), hemoglobin A1c (HbA1c), total protein (TP), albumin (Alb), urea nitrogen $(\mathrm{UN})$, creatinine (Cre), sodium $(\mathrm{Na})$, potassium $(\mathrm{K})$, chloride $(\mathrm{Cl})$, calcium $(\mathrm{Ca})$, phosphorus $(\mathrm{Pi})$, intact parathyroid hormone $(\mathrm{PTH})$ and intact FGF23 (FGF23) levels were measured by SRL Inc.

\section{Statistical analysis}

Data were described as means \pm SD. The data were tested for normality using the Shapiro-Wilk test. All statistical analyses were performed with SPSS Statistic, version 19.0 for Windows (19892010, SPSS, Inc., an IBM Company, US) and were considered statistically significant at $\mathrm{P}<0.05$. Pearson's correlation coefficient was used to evaluate association between UC-P and serum FGF23 levels. Two-sample t-tests and Mann-Whitney tests were used to compare serum FGF23 levels, serum FGF23 levels/UC-P and serum FGF23 levels/UC-P/BW between the male and female groups. 


\section{RESULTS}

\section{Subject characteristics}

The characteristics of the subjects are shown in Table 1. Mean age was $22.1 \pm 1.5$ years and body mass index was $21.0 \pm 2.7 \mathrm{~kg} / \mathrm{m}^{2}$. Subjects had normal glucose and lipid metabolism, hepatic function and renal function.

The association between UC-P and serum FGF23 levels

Positive correlation was observed between UC-P and serum FGF23 levels $(\mathrm{r}=0.35 ; \mathrm{P}<0.01)$ (Figure 1$)$.

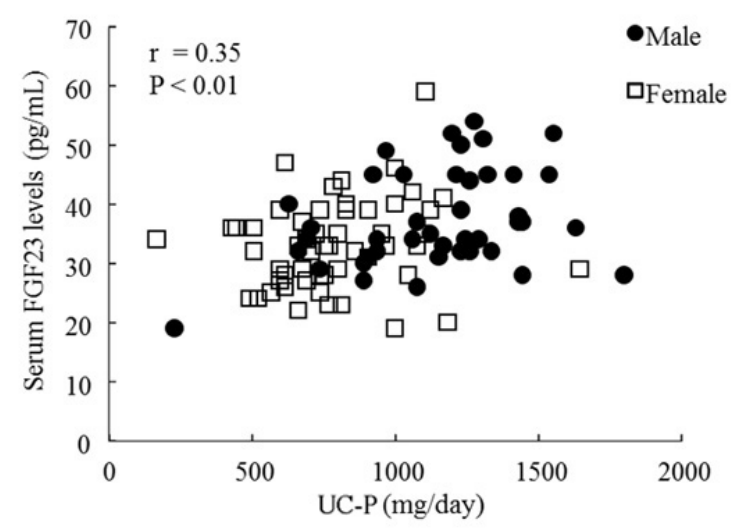

Figure 1. Univariate association between UC-P and serum FGF23 levels.

Pearson's product moment correlation coefficient $(\mathrm{r})$ and its $\mathrm{P}$ value are represented. Closed circle : male; open square : female. UC : estimated intake calculated by 24 -hour urine collection.
Serum FGF23 levels comparisons between males and females

To evaluate whether sex could influence FGF23 responsiveness to dietary phosphorus intake, serum FGF23 levels were compared between male and female subjects (Figure 2). Serum FGF23 levels were significantly higher in males than in females (37.4 \pm 8.2 $\mathrm{pg} / \mathrm{ml}$ and $33.1 \pm 7.5 \mathrm{pg} / \mathrm{ml}$, respectively) $(\mathrm{P}<0.05)$ (Figure $2 \mathrm{a})$. UC-P was also significantly higher in males compared to females $(1141 \pm 308 \mathrm{mg} /$ day and $788 \pm 264 \mathrm{mg} /$ day, respectively $)(\mathrm{P}<0.01)$ (Figure $2 \mathrm{~b}$ ). However, serum FGF23 levels/UC-P was significantly higher in females than in males $(\mathrm{P}<0.01)$. Serum levels/UC-P in males was $0.035 \pm 0.012 \mathrm{pg} / \mathrm{ml}$ and in females was $0.047 \pm 0.025$ $\mathrm{pg} / \mathrm{ml}$ (Figure 2c). UC-P/BW was significantly higher in males than in females $(17.4 \pm 4.3 \mathrm{mg} / \mathrm{kg}$ and $15.6 \pm 4.9 \mathrm{mg} / \mathrm{kg}$, respectively) $(\mathrm{P}<0.05)$ (Figure 2d). To examine the effect of UC-P/BW on serum FGF23 levels, we analyzed sex differences in serum FGF23 levels/UC-P/BW. There was no significant difference in serum FGF23 levels/UC-P/BW between males and females (2.3 \pm $0.7 \mathrm{pg} / \mathrm{ml}$ and $2.4 \pm 1.5 \mathrm{pg} / \mathrm{ml}$, respectively) $(\mathrm{P}=0.95)$ (Figure $2 \mathrm{e})$.

\section{DISCUSSION}

This study evaluated whether sex influenced FGF23 responsiveness to dietary phosphorus intake. UC-P and serum FGF23 levels were positively associated. FGF23 contributed to phosphorus homeostasis through suppression of renal phosphorus reabsorption and intestinal phosphorus absorption $(18,19)$. In a previous study, using a phosphorus loading test with three test meals containing different phosphorus levels $(400 \mathrm{mg} / \mathrm{meal}$ : P400, $800 \mathrm{mg} / \mathrm{meal}$ : P800, and $1200 \mathrm{mg} / \mathrm{meal}$ : P1200), serum FGF23 levels were little changed after P400 and P800 loading, but significantly increased at $8 \mathrm{~h}$ after P1200 loading (6). Another study reported that serum FGF23 levels were significantly higher after $2500 \mathrm{mg}$ phosphorus
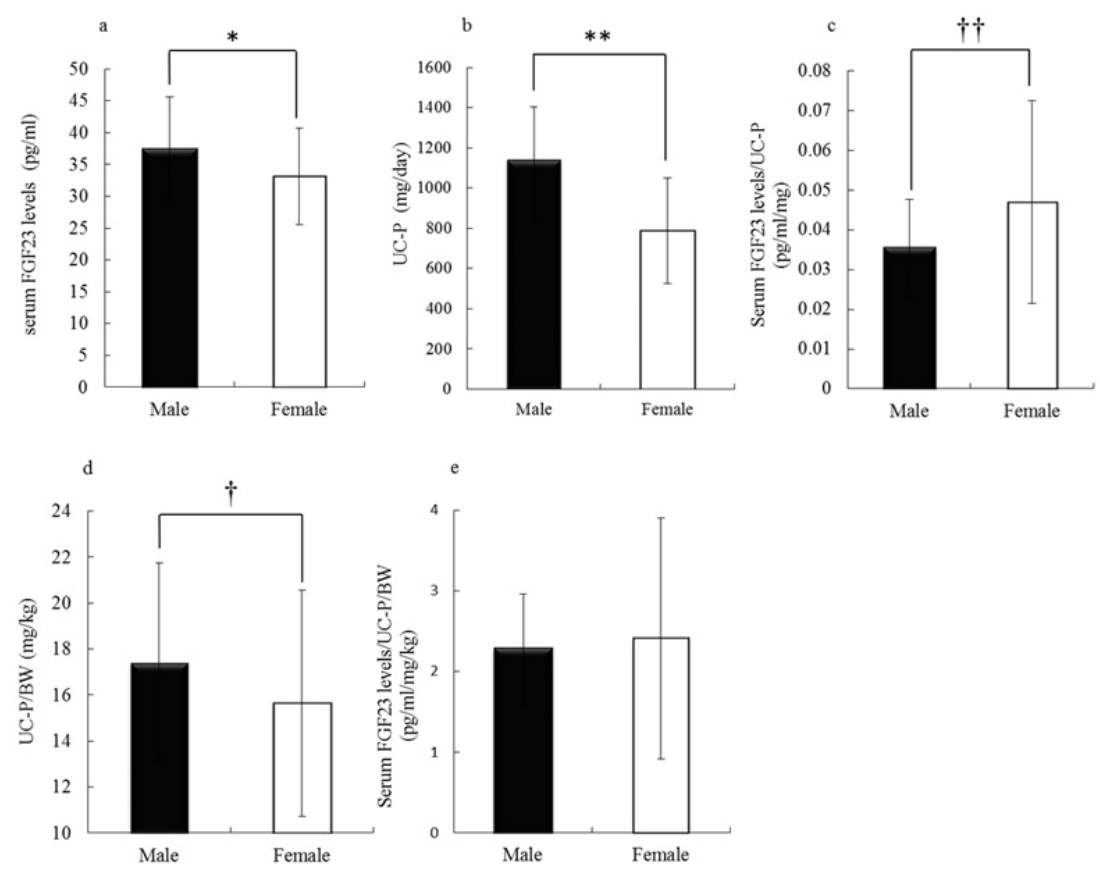

Figure2. Sex comparison of serum FGF23 levels.

Serum FGF23 levels (a), UC-P (b), serum FGF23 levels/UC-P (c), UC-P/BW (d), serum FGF23 levels/UC-P/BW (e). *P<0.05 : male vs female by two-sample $\mathrm{t}$-test. ${ }^{*} * \mathrm{P}<0.01$ : male vs female by two-sample $\mathrm{t}$-test. ${ }^{\dagger} \mathrm{P}<0.05$ : male vs female by Mann-Whitney test. ${ }^{\dagger}{ }^{\dagger} \mathrm{P}<0.01:$ male vs female by Mann-Whitney test. 
loading than after $500 \mathrm{mg}$ phosphorus loading (20). Therefore, the association between UC-P and serum FGF23 levels observed in this study suggests that FGF23 was secreted in response to the amount of phosphorus ingested in order to maintain phosphorus homeostasis, however, the correlation was weak $(r=0.35 ; \mathrm{P}<$ 0.01 ). We previously reported that the 24 -hour urine collection method could be used to estimate diurnal dietary phosphorus intake (17). It is considered that serum FGF23 levels might be affected by prolonged phosphorus intake, PTH $(21), 1,25(\mathrm{OH})_{2} \mathrm{D}$ (21) and genetic factor such as single nucleotide polymorphism $(22,23)$, which might be one of the reasons for a weak association between UC-P and serum FGF23 levels. In this study, associations between serum FGF23 levels and these factors were not investigated, so we needed to investigate these associations in the future study.

We compared UC-P and serum FGF23 levels between male and female subjects to evaluate whether sex could influence FGF23 responsiveness to dietary phosphorus intake. Serum FGF23 levels were significantly higher in males compared to females. However, serum FGF23 levels/UC-P was significantly higher in females than in males. There was no significant difference in serum FGF23 levels/UC-P/BW between male and female subjects. Male subjects had significantly higher UC-P/BW compared with females. These results suggest that there is no difference in FGF23 responsiveness to phosphorus intake per body weight between males and females, but UC-P/BW in males was higher than in females and as a result, serum FGF23 levels was significantly higher in males. The recommended intake amounts of phosphorus are 1000 $\mathrm{mg}$ /day for adult males and $900 \mathrm{mg} /$ day for adult females, and the tolerable upper limit of phosphorus intake is $3000 \mathrm{mg} /$ day for both adult males and females in Japan (24). The results of this study suggest that recommended intake and tolerable upper limit of phosphorus intake needs to be established according to body weight.

A previous study reported that serum FGF23 levels in postmenopausal females were significantly higher than in males, and were decreased by estrogen therapy (16). Since the estrogen receptor is present at the proximal tubule which regulates urinary phosphorus excretion, it has been suggested that serum phosphorus levels are increased by hormonal imbalance with menopause, and FGF23 secretion is increased. A previous study suggested that serum phosphorus levels are higher in postmenopausal females compared with menstruating females (25). It is also reported that postmenopausal status is associated with higher serum phosphorus levels (26). The female subjects in this study were premenopausal, suggesting there would be no difference in serum FGF23 levels/UC-P/BW between male and female subjects, however, estrogen was not measured in this study and it is unclear whether estrogen influenced FGF23 responsiveness to phosphorus intake.

Phosphorus intake and serum FGF23 levels correlated in all subjects in this study however, the correlation was weaker in female subjects (data not shown). There are two possible reasons for these results : the female subjects in this study may have paid more attention to their diet and body habitus compared to male subjects (27). The variation in body weight, body fat mass and lean body mass of the female subjects were smaller when compared with the male subjects. Phosphorus intake in females was significantly lower than that in males, and there was no difference in variation in data. Recently, it has been shown that leptin stimulates FGF23 production in bone (28). Plasma leptin levels are increased in obesity, and are strongly associated with body fat mass (29). Administration of intraperitoneal leptin in ob/ob mice increased FGF23 mRNA in the bones and serum FGF23 levels (28) and serum leptin levels were significantly higher in a human study group with high serum FGF23 levels compared with a low serum FGF23 level study group (30). It has also been reported that serum FGF23 levels are associated with body fat mass and percent body fat. In our study, the female subject's body fat was distributed in a narrow range, so association between phosphorus intake and serum FGF23 levels was found to be weaker in female subjects compared with male subjects. The second reason for the weaker correlation is that the estradiol cycle (menstrual cycle) may influence FGF23 secretion. In this study, test days were selected to fall outside the menstrual periods of the female subjects, but we did not adjust for phase of menstrual cycle. The difference in menstrual cycle phase among individual females might effect FGF23 secretion. Further studies on menstrual cycle and serum estrogen levels are required to reveal whether sex could influence FGF23 responsiveness to phosphorus intake.

Our results indicate that sex had no effect on FGF23 responsiveness to phosphorus intake per body weight. Though recommended intake amounts of phosphorus are uniformly established, our results suggest that it should be recalculated on the basis of body weight. Further studies examining the influence of sex and physical constitution on FGF23 responsiveness to dietary phosphorus intake are needed to establish recommended intake amounts of phosphorus.

\section{CONFLICT OF INTEREST}

All authors declare that they had no conflict of interest.

\section{ACKNOWLEDGEMENTS}

This study was supported by Grant-in-Aid for Young Scientists (B) 26750046 from the Ministry of Education, Culture, Sports, Science and Technology in Japan.

\section{REFERENCES}

1. Vervloet MG, van Ittersum FJ, Büttler RM, Heijboer AC, Blankenstein MA, ter Wee PM : Effects of dietary phosphate and calcium intake on fibroblast growth factor-23. Clin J Am Soc Nephrol 6 : 383-389, 2011

2. Kendrick J, Chonchol M : The role of phosphorus in the development and progression of vascular calcification. Am J Kidney Dis 58 : 826-834, 2011

3. Block GA, Port FK : Re-evaluation of risks associated with hyperphosphatemia and hyperparathyroidism in dialysis patients : recommendations for a change in management. Am J Kidney Dis 35 : 1226-1237, 2000

4. Ganesh SK, Stack AG, Levin NW, Hulbert-Shearon T, Port FK : Association of elevated serum PO(4), Ca x PO(4) product, and parathyroid hormone with cardiac mortality risk in chronic hemodialysis patients. J Am Soc Nephrol 12 : 21312138, 2001

5. Shuto E, Taketani Y, Tanaka R, Harada N, Isshiki M, Sato M, Nashiki K, Amo K, Yamamoto H, Higashi Y, Nakaya Y, Takeda $\mathrm{E}$ : Dietary phosphorus acutely impairs endothelial function. J Am Soc Nephrol 20 : 1504-1512, 2009

6. Nishida Y, Taketani Y, Yamanaka-Okumura H, Imamura F, Taniguchi A, Sato T, Shuto E, Nashiki K, Arai H, Yamamoto $\mathrm{H}$, Takeda $\mathrm{E}$ : Acute effect of oral phosphate loading on serum fibroblast growth factor 23 levels in healthy men. Kidney Int $70: 2141-2147,2006$

7. Antoniucci DM, Yamashita T, Portale AA : Dietary Phosphorus Regulates Serum Fibroblast Growth Factor-23 Concentrations in Healthy Men. J Clin Endocrinol Metab 91 : 31443149,2006 
8. Ferrari SL, Bonjour JP, Rizzoli R : Fibroblast Growth Factor23 Relationship to Dietary Phosphate and Renal Phosphate Handling in Healthy Young Men. J Clin Endocrinol Metab 90 : 1519-1524, 2005

9. Portale AA, Halloran BP, Morris RC Jr : Physiologic Regulation of the Serum Concentration of 1,25-Dihydroxyvitamin D by Phosphorus in Normal Men. J Clin Invest 83 : 1494-1499, 1989

10. Miyamoto K, Ito M, Kuwahata M, Kato S, Segawa H : Inhibition of Intestinal Sodium-dependent Inorganic Phosphate Transport by Fibroblast Growth Factor 23. Ther Apher Dial $9: 331-335,2005$

11. Yu X, White KE : FGF23 and disorders of phosphate homeostasis. Cytokine Growth Factor Rev 16 : 221-232, 2005

12. Shimada T, Mizutani S, Muto T, Yoneya T, Hino R, Takeda S, Takeuchi Y, Fujita T, Fukumoto S, Yamashita T: Cloning and characterization of FGF23 as a causative factor of tumor-induced osteomalacia. Proc Natl Acad Sci USA 98 : 6500-6505, 2001

13. ADHR Consortium : Autosomal dominant hypophosphataemic rickets is associated with mutations in FGF23. Nat Genet 26 : 345-348, 2000

14. Nakai K, Komaba H, Fukagawa $\mathrm{M}$ : New insights into the role of fibroblast growth factor 23 in chronic kidney disease. J Nephrol 23 : 619-625, 2010

15. Carriollo Lopez N, Roman Garicia P, Rodriguez Rebollar A, Fernández-Martín JL, Naves-Díaz M, Cannata-Andía JB : Indirect regulation of PTH by estrogen of PTH by estrogens may require FGF23. J Am Soc Nephrol 20 : 2009-2017, 2009

16. Ix JH, Chonchol M, Laughlin GA, Shlipak MG, Whooley MA : Relation of sex and estrogen therapy to serum fibroblast growth factor 23, serum phosphorus, and urine phosphorus : the Heart and Soul Study. Am J Kidney Dis 58 : 737-745, 2011

17. Morimoto Y, Sakuma M, Ohta H, Suzuki A, Matsushita A, Umeda M, Ishikawa M, Taketani Y, Takeda E, Arai H : Estimate of dietary phosphorus intake using 24 -h urine collection. J Clin Biochem Nutr 55 : 62-66, 2014

18. Shimada T, Hasegawa H, Yamazaki Y, Muto T, Hino R, Takeuchi Y, Fujita T, Nakahara K, Fukumoto S, Yamashita T: FGF-23 is a potent regulator of vitamin D metabolism and phosphate homeostasis. J Bone Miner Res 19 : 429-435, 2004

19. Saito H, Kusano K, Kinosaki M, Ito H, Hirata M, Segawa H, Miyamoto K, Fukushima N : Human fibroblast growth factor23 mutants suppress $\mathrm{Na}$--dependent phosphate co-transport activity and 1alpha,25-dihydroxyvitamin D3 production. J Biol Chem 278 : 2206-2211, 2003
20. Burnett SM, Gunawardene SC, Bringhurst FR, Jüppner H, Lee H, Finkelstein JS : Regulation of C-terminal and intact FGF-23 by dietary phosphate in men and women. J Bone Miner Res $21: 1187-1196,2006$

21. Martine A, David V, Quarles LD : Regulation and function of the FGF23/klotho endocrine pathways. Physiol Rev 92 : 131155,2012

22. Araya K, Fukumoto S, Backenroth R, Takeuchi Y, Nakayama K, Ito N, Yoshii N, Yamazaki Y, Yamashita T, Silver J, Igarashi T, Fujita T : A novel mutation in fibroblast growth factor 23 gene as a cause of tumoral calcinosis. J Clin Endocrinol Metab $90: 5523-5527,2005$

23. Larsson T, Davis SI, Garringer HJ, Mooney SD, Draman MS, Cullen MJ, White KE : Fibroblast growth factor-23 mutants causing familial tumoral calcinosis are differentially processed. Endocrinology $146: 3883-3891,2005$

24. Ministry of Health, Labour and Welfare (MHLW) 2010 edition. Dietary Reference Intakes in Japan. MHLW, Tokyo : Daiichisyuppan, 2009 (in Japanese)

25. Cirillo M, Ciacci C, De Santo NG : Age, renal tubular phosphate reabsorption, and serum phosphate levels in adults. $\mathrm{N}$ Engl J Med 359 : 864-866, 2008

26. Onufrak SJ, Bellasi A, Cardarelli F, Vaccarino V, Muntner P, Shaw LJ, Raggi P : Investigation of gender heterogeneity in the associations of serum phosphorus with incident coronary artery disease and all-cause mortality. Am J Epidemiol 169 : 67-77, 2009

27. Takimoto H, Yoshiike N, Kaneda F, Yoshita K: Thinness among young Japanese women. Am J Public Health 94 : 15921595,2004

28. Tsuji K, Maeda T, Kawane T, Matsunuma A, Horiuchi N : Leptin stimulates fibroblast growth factor 23 expression in bone and suppresses renal 1alpha,25-dihydroxyvitamin D (3) synthesis in leptin-deficient ob/ob mice. J Bone Miner Res $25: 1711-1723,2010$

29. Considine RV, Sinha MK, Heiman ML, Kriauciunas A, Stephens TW, Nyce MR, Ohannesian JP, Marco CC, McKee LJ, Bauer TL, Caro JF : Serum immunoreactiveleptin concentrations in normal-weight and obese humans. N Engl J Med $334: 292-295,1996$

30. Mirza MA, Alsio J, Hammarstedt A, Erben RG, Michaëlsson K, Tivesten A, Marsell R, Orwoll E, Karlsson MK, Ljunggren O, Mellström D, Lind L, Ohlsson C, Larsson TE : Circulating fibroblast growth factor-23 is associated with fat mass and dyslipidemia in two independent cohorts of elderly individuals. Arterioscler Thromb Vasc Biol 31 : 219-227, 2011 